\title{
Applications of Nanoparticles for MRI Cancer Diagnosis and Therapy
}

\author{
Barbara Blasiak, ${ }^{1,2}$ Frank C. J. M. van Veggel, ${ }^{3}$ and Boguslaw Tomanek ${ }^{1,2,4,5}$ \\ ${ }^{1}$ Institute of Nuclear Physics, Polish Academy of Sciences, 31-342 Krakow, Poland \\ ${ }^{2}$ Department of Clinical Neurosciences, University of Calgary, AB, Canada T2N 4N1 \\ ${ }^{3}$ Department of Chemistry, University of Victoria, Victoria, BC, Canada V8W 3V6 \\ ${ }^{4}$ Thunder Bay Regional Research Institute, Thunder Bay, ON, Canada P7B 6V4 \\ ${ }^{5}$ Department of Oncology, University of Alberta, AB, Canada T6G $1 Z 2$
}

Correspondence should be addressed to Barbara Blasiak; bblasiak@ucalgary.ca

Received 21 June 2013; Accepted 5 August 2013

Academic Editor: Tifeng Jiao

Copyright (c) 2013 Barbara Blasiak et al. This is an open access article distributed under the Creative Commons Attribution License, which permits unrestricted use, distribution, and reproduction in any medium, provided the original work is properly cited.

Recent technological advances in nanotechnology, molecular biology, and imaging technology allow the application of nanomaterials for early and specific cancer detection and therapy. As early detection is a prerequisite for successful treatment, this area of research has been rapidly growing. This paper provides an overview of recent advances in production, functionalization, toxicity reduction, and application of nanoparticles to cancer diagnosis, treatment, and treatment monitoring. This review focuses on superparamagnetic nanoparticles used as targeted contrast agents in MRI, but it also describes nanoparticles applied as contrasts in CT and PET. A very recent development of core/shell nanoparticles that promises to provide positive contrast in MRI of cancer is provided. The authors concluded that despite unenviable obstacles, the progress in the area will lead to rapidly approaching applications of nanotechnology to medicine enabling patient-specific diagnosis and treatment.

\section{Introduction}

Despite many efforts, cancer is among the top three causes of death in modern society [1], demanding improved treatment, that currently includes surgery, chemotherapy, and various types of radiation therapy. Although there is a substantial progress in effective cancer treatment and many forms of cancer are treatable, the therapies are not always effective and often have undesired side-effects [1]. As early diagnosis is essential for successful therapy, both new diagnosis and treatment methods need to be developed. Nanotechnology, combined with other disciplines such as molecular biology and imaging technology, provides unique capabilities and enables innovative diagnosis and therapy. Furthermore, it also allows individualized treatment and treatment monitoring, taking into account patients' variability and thus their response to treatment, ensuring optimal efficacy of the applied therapy. While this technology is currently mostly applied to various types of cancer, it could soon find applications to other diseases.

\section{Nanomaterials in Cancer Diagnosis}

As early diagnosis is associated with positive outcome, using any type of therapy, there are many incentives for developing technologies that can detect cancer at its earliest stages. In most cases, detection of stage 1 cancers is associated with a higher than 90\% 5-year survival rate [2, 3] due to availability of curative treatment.

Currently, cancer is detected using various medical tests such as blood, urine, or imaging techniques followed by biopsy. Conventional anatomical imaging techniques typically detect cancers when they are few millimeters (e.g., MRI) or centimetres (e.g., PET) in diameter, at which time they already consist of more than a million cells. Recently proposed molecular imaging aims at rectifying this disadvantage. The development of this new imaging modality became possible due to the recent progress in nanotechnology, molecular and cell biology, and imaging technologies. While molecular imaging applies to various imaging techniques such as Positron Emission Tomography (PET), computed tomography 
(CT), or ultrasound, of particular interest is magnetic resonance imaging (MRI) that provides the best spatial resolution when compared to other techniques and is noninvasive or at least minimally invasive. Unfortunately, MRI has not been applied to its full potential for the diagnosis of cancer mostly because of its low specificity (false-positive rate of $10 \%$ for breast cancer) [4-8]. The lack of MRI specificity can be, however, rectified using cell markers and unique properties of paramagnetic and superparamagnetic nanoparticles (NP), which can be utilized to be detected with MRI in small quantities. Super(paramagnetic) nanoparticles when placed in the magnetic field disturb the field causing faster water proton relaxation, thus enabling detection with MRI.

Nanoparticles, typically smaller than $100 \mathrm{~nm}$, have been applied to medicine $[9,10]$ due to their unique magnetic properties and sizes, comparable to the largest biological molecules, such as enzymes, receptors, or antibodies, that enable diagnostic, therapy as well as combined therapy and diagnostic (known as theranostics) [11, 12]. Nanoparticles with potential MRI-related medical applications comprise various materials, such as metals (gold, silver, and cobalt) or metal oxides $\left(\mathrm{Fe}_{3} \mathrm{O}_{4}, \mathrm{TiO}_{2}\right.$, and $\left.\mathrm{SiO}_{2}\right)$.

A passive or active method can be used to deliver nanoparticles to the specific site. An example of passive application of iron-based nanoparticles is liver cancer that lacks an efficient method of early diagnosis. Current techniques, including ultrasound, CT, and MRI, detect liver tumors only when they have grown to about 5 centimeters in diameter. By that time, the cancer is especially aggressive, resisting chemotherapy, and difficult to remove surgically. Application of ironbased nanoparticles improved MRI sensitivity due to accumulation of iron in the liver caused by selective action of the hepatobiliary system (Figure 1). This type of contrast delivery does not apply, however, to most of the cancers thus targeted, and active delivery is used.

From the point of view of MRI technique, to increase MRI sensitivity, two types of contrast agents, providing positive or negative image contrast, are used. Contrast agents comprising gadolinium $(\mathrm{Gd})$ or manganese $(\mathrm{Mn})$ provide hyperintense $T_{1}$-weighted tumor images [13-16], while superparamagnetic nanoparticles reduce $T_{2}$ and $T_{2}{ }^{*}$ of surrounding water molecules, thus decreasing MR signal in $T_{2}$ - and $T_{2}{ }^{*}$-weighted MRI (negative image contrast) in the areas corresponding to the location of the disease [17]. Gadolinium (III), with its high electron magnetic moment, is the most common $T_{1}$ contrast agent, that provides nonspecific positive $T_{1}$ contrast.

Free $\mathrm{Gd}^{3+}$ is toxic $\left(\mathrm{LD}_{50}=0.2 \mathrm{mmol} \mathrm{kg}^{-1}\right.$ in mice $)$; therefore, it is administered in the form of stable chelate complexes that prevent the release of the metal ion in vivo [18]. Following intravascular injection, nonspecific Gd-based compounds distribute rapidly between plasma and interstitial spaces and are ultimately eliminated through the renal route with halflives of about 1.6 h [18]. Polyaminocarboxylate ligands, which incorporate nitrogen and oxygen donor atoms, are used to coordinate the Gd center. The Gd-based contrast agents are provided commercially by various suppliers. Accumulation of these contrast agents is solely based on differences in the vasculature between tumor and normal tissues; thus, MRI recognition of specific tumor types is not achieved. Molecular
MR imaging rectifies this drawback by taking advantage of the distinctive cell properties (such as a unique pattern of protein expression) of the tumor and combines them with superparamagnetic nanoparticles enabling both sensitive and specific detection of molecular targets associated with early events in carcinogenesis [2]. To enable MR specificity, nanoparticles may be conjugated with various organic vehicles (Figure 2), for example, with single domain antibodies $(\mathrm{sdAb})$ that are specific for proteins that are overexpressed on the surface of the tumor cells, in the tumor microenvironment (e.g., the extracellular matrix (ECM)), or by the tumor vasculature.

There are various corresponding receptors such as epidermal growth factor receptor (EGFR), a cell surface receptor known to be overexpressed, for example, in the triple negative (TN) breast cancers or secreted clusterin (sCLU), and a protein that is secreted into the microenvironment and that has been shown to be associated with the progression of primary to metastatic carcinoma. Insulin Growth Factor Binding Protein 7 (IGFBP-7) has been shown to be specifically overexpressed by the tumor vasculature; it can also be used as a vascular target $[19,20]$. The agents against these selected targets can be developed using single domain antibodies that have been shown to specifically bind to these targets. Such a probe allows localization of the disease in vivo, and potentially gives insight into biological processes (e.g., angiogenesis and metastasis) which are critical to tumor development and can, therefore, be used to monitor the response of a tumor to individualized therapy. This way, treatment may be applied at a curable stage and adjusted if needed. Furthermore, MRI, in particular when combined with application of nanoparticles, has a capability in cancer staging, following up the progress of treatment, and accurate detection of lymph nodes involvement in disease [21] as showed in the recently reported detection of small and otherwise undetectable lymph node metastases in patients with prostate cancer $[22,23]$.

\section{Therapeutic Applications of Nanoparticles}

While diagnostic is a common medical application of nanoparticles, they can also be used for therapy $[9,24,25]$. Their properties offer unique interactions with biomolecules both on the surface and inside the cells, enabling significant improvement in cancer diagnosis and treatment [26]. Therefore, nanoparticles have been recently utilized by biologists, pharmacologists, and physicists, physicians as well as the pharmaceutical industry [27].

There are about 20 clinically approved nanomedicines used for treatment. An example is Abraxane, an albuminbound form of paclitaxel with Cobalt of mean particle size of approximately $130 \mathrm{~nm}$ that is used to treat breast cancer [28]. Doxil, also based on Cobalt, is used for the treatment of refractory ovarian cancer and AIDS-related Kaposi's sarcoma and it consists of nanoparticles with a polyethylene glycol (PEG) coating $[11,29,30]$.

A primary attribute of nanoparticles delivery systems is their potential to enhance the accumulation of anticancer agents in tumor cells as some nanoparticles passively accumulate in tumors after their intravenous administration $[1,28,31-33]$. Nanoparticles can penetrate through small 


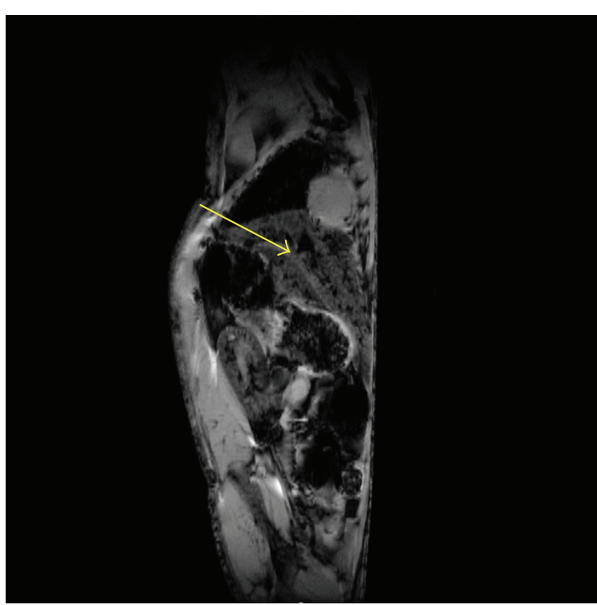

(a)

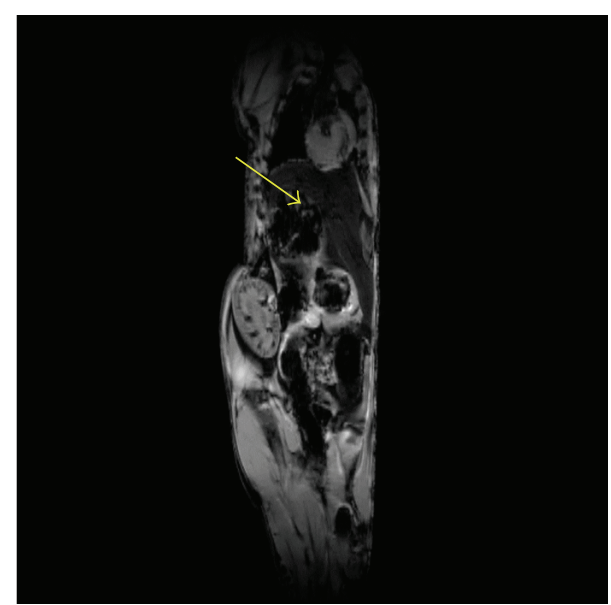

(b)

Figure 1: An MR image (gradient echo, TR/TE $=100 \mathrm{~ms} / 4 \mathrm{~ms}$, flip angle $30^{\circ}$, FOV $=5.5 \mathrm{~cm} \times 2.5 \mathrm{~cm}, 256 \times 256$ ) of a mouse liver obtained at 9.4T before (a) and after (b) injection of iron oxide (Nano-Ocean, USA). Decrease of MR signal within the liver (yellow arrow) is visible.

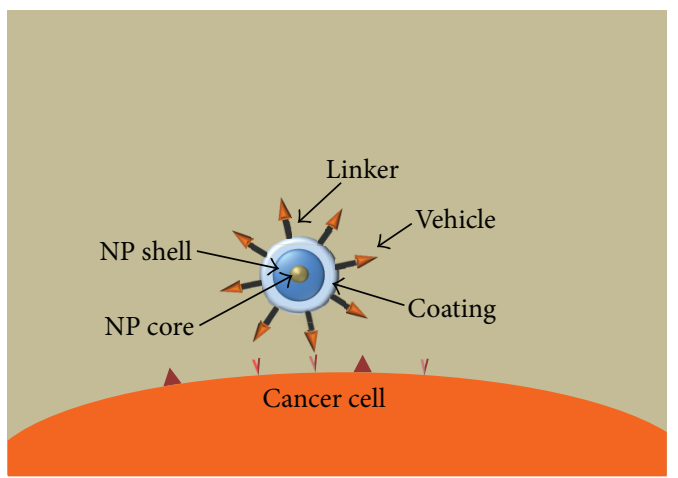

FIGURE 2: Schematic representation of a targeted contrast agent used for MRI approaching of the cancer cell and expressing specific proteins (modification from [19]).

capillaries and are taken up by cells, which allow efficient drug accumulation at target sites enabling also a sustained and controlled release of drugs at target sites over a period of days or even weeks [1, 28, 31-33]. In general, drug targeting by nanoparticles or nanocapsules reduces dosage, ensures the pharmaceutical effects, minimizes side-effects, and enhances drug stability $[1,34-36]$.

Bare nanoparticles are inherently unstable under physiological conditions; thus, they are coated with biocompatible polymers that improve colloidal stability in biological media preventing agglomeration and subsequent precipitation.

Colloidal nanoparticle systems for biomedical applications should also exhibit low toxicity and possess a long shelf life [12]. Therefore, magnetic nanoparticles are the subject of intense research focusing on their synthesis, characterization, biocompatibility, and functionalization $[13,37]$. The organic coating may also provide a means for delivery of drugs or/and bioconjugation of biological vehicles (e.g., antibodies), thus enabling transportation to the specific disease site $[9,38]$. A protective layer increases circulation half-life by preventing action of the immune system and allows for the addition of targeting agents. [11, 30, 39-42]. The core particle is often protected by several monolayers of inert material $[9,17]$, that composition depends on its application. Various research groups have studied the effect of nanoparticle coating on cellular toxicity [9]. For example, Goodman and colleagues [43] demonstrated that cationic nanoparticles were moderately toxic, while as-anionic nanoparticles were nontoxic $[9,43]$. The authors found that nanoparticles functionalized with quaternary ammonium have mild effects on cell viability, while carboxy-functionalized nanoparticles do not have effects [9, 43]. Pisanic et al. [44] found that magnetic nanoparticles coated with dimercaptosuccinic acid (DMSA) were toxic to neurons in a dose-dependent manner [44] while Wilhelm and colleagues [45] have shown that DMSA coated nanoparticles are non-toxic to HeLa cells or RAW macrophages $[9,45]$. The most common coatings are polyethylene glycol (PEG) [46], polyvinyl alcohol (PVA) [47], polysaccharides chitosan [48], dextran [49], carboxymethyl dextran (CMDx) [50], starch, albumin, silicones, or polyvinylpyrrolidone (PVP) $[9,51]$. While the same layer might act as a biocompatible material, more often an additional layer of linker molecules is used to improve further functionalization. The linear linker molecule has reactive groups at both ends. One group is aimed at attaching the linker to the nanoparticle surface and the other is used to bind various moieties like proteins, antibodies, or fluorophores, depending on the application [17], creating a targeted contrast agent $[9,52]$. The choice of material, its size, and the way in which it is coated or protected becomes of great importance in moving a nanoparticle into clinical use [11].

The most commonly used method of drug delivery is the antibody- or ligand-mediated targeting of anticancer therapeutics similarly as in molecular imaging diagnostic. The basic principle that underlies ligand-targeted therapeutics is that the selective delivery of drugs to cancer cells or tumor vasculature can be enhanced by synthesising the drugs with molecules that bind to antigens or receptors that are either 
uniquely expressed or over-expressed on target cells $[1,53-$ 56]. The use of new synthesis techniques, such as condensation reactions, allowed the incorporation of various targeting ligands to the nanoparticle shell, including EGF-related targets $[11,57,58]$, transferrin $[11,59,60]$, lactoferrin $[11,61]$, transactivating transcriptional activator [11, 62], aptamers [11, $63]$, and numerous other peptides such as chlorotoxin [11, 64$68]$. For example, the use of the peptide sequence known as Angiopep has recently become important for the targeting of brain cancer $[11,69]$ as both the BBB and gliomas are known to overexpress the corresponding receptors [11, 69]. Many researchers have recently utilized various coatings to improve the drug delivery. For example, Veiseh et al. [66, 70] found that the incorporation of chlorotoxin onto functionalized $\mathrm{Fe}_{3} \mathrm{O}_{4}$ nanoparticles resulted in a significant increase in the total uptake within the brain tumors of mice after in vivo injection when compared with untargeted particles; Kim and coworkers found that hydrophobic drugs could be incorporated into monolayers of polyelectrolyte-coated gold nanoparticles for cellular delivery [11, 71]. Liu et al. utilized polymer-coated magnetic nanoparticles to deliver the anticancer drug epirubicin and to provide an MRI contrast agent for brain cancer $[11,72]$.

An example of an organic-based delivery vehicle is liposomes, which are spherical in shape and consist of a phospholipid shell that can be used to encapsulate and deliver both hydrophobic and hydrophilic drugs [11]. They are on average $100 \mathrm{~nm}$ in diameter [41,73-75]. Doxorubicin was the first drug to be delivered by liposomes to brain tumors [11, $41,74,75]$. High-density lipoprotein (HDL) nanoparticles are closely related to liposomal nanocarriers, having the stability and monodispersity of inorganic nanoparticles combined with the shielding ability of liposomes that improve circulation half-lives of therapeutics [76-78].

Nanoparticles with controllable sizes ranging from a few nanometers up to tens of nanometers are of particular interest. They are thousands of times smaller than cells and comparable with viruses, proteins, and genes. Therefore, they are able to cross biological membranes, interact closely with biomolecules enabling access to intra- and extracellular spaces thus inducing various responses in biological systems [79] and improving cancer therapy and/or diagnosis. Nanoparticles provide a means to increase transport across the $\mathrm{BBB}$ and/or blood-brain-tumor barrier (BBTB) and for this reason have been exploited in the treatment of brain cancer [11, 8086]. For example, nanoparticles are promising in glioma treatment. This brain cancer is particularly difficult to treat $[11,87,88]$ as neurosurgery is ineffective, while chemotherapy suffers from the inability of therapeutics to cross the bloodbrain barrier (BBB). Several different types of nanoparticles have been employed as imaging and delivery agents for brain cancer treatment, including $\mathrm{Fe}_{3} \mathrm{O}_{4}$ nanoparticles [11, 42, 66, 70, 89-93], gadolinium [81,94-96], gold [97], semiconductor quantum [QDs] [11, 58, 98], and organic-based (dendrimer, hydrogel, and polymer) nanoparticles $[11,64,67,68,73,99-$ 101].

While nanoparticles can function as delivery vehicles with variable sizes, shapes, and surfaces that serve to increase bioavailability and specificity of cancer therapeutics, they can also allow loading of additional drugs for simultaneous multidrug delivery. The addition of imaging probes may be utilized for simultaneous diagnosis, therapy, and monitoring. Finally, toxicity of nanoparticles could also be potentially utilized to destroy the cancer cells [11, 41, 102-104].

Although not yet fully developed, methods of activation of nanoparticles after reaching the target are being investigated. An example is the use of metallic nanoparticles that can be heated with light, radiofrequency, or magnetic fields for thermal ablation of tumors [17, 43-46, 105-107]. The oscillating magnetic field can be applied after the particles reach the tissue of interest, as determined, for example, by MRI. The drug release is induced by the temperature increase generated by the magnetic nanoparticles subject to an oscillating magnetic field. This temperature increase is then utilized to stimulate a thermoresponsive polymer synthesised to the nanoparticle surface.

\section{Iron-Based Nanoparticles}

The inorganic nanoparticles that have been applied clinically are mainly nanoparticles based on iron oxide, $\mathrm{Fe}_{3} \mathrm{O}_{4}$, with diameters around $50 \mathrm{~nm}$ as these nanoparticles have been relatively well-tolerated.

The most common and the first to be applied in MRI nanoparticle is the so-called small and ultrasmall superparamagnetic iron oxide (SPIO and USPIO, resp.). SPIONs are typically monocrystalline composed of magnetite $\left(\mathrm{Fe}_{3} \mathrm{O}_{4}\right)$ or maghemite $\left(\gamma-\mathrm{Fe}_{2} \mathrm{O}_{4}\right)[22]$. Because iron oxide has a relatively low saturation magnetization, it requires the use of large particles to achieve sufficient MRI contrast [4]. Iron oxide nanoparticles vary in size and may have different types of surface coating, which significantly affect their blood half-life, biodistribution, and uptake. The synthesis method utilized to produce SPIO nanoparticles determines the size and polydispersity of the particle population $[5,6]$.

Magnetic iron oxide particles have been used clinically since 1987, when they were applied for the detection of focal liver and spleen lesions with MRI. SPIOs, with hydrodynamic diameter larger than $30 \mathrm{~nm}$, tend to have a short blood halflife as they are taken up by mononuclear phagocytosing system (MPS) in liver and spleen, leading to a significant MR signal loss in these tissues in $T_{2}$-weighted MR images [22, 108]. Focal liver lesions without an MPS or without an intact MPS do not show this accumulation and maintain their precontrast signal intensity [22]. Thus, SPIO-enhanced MRI shows an increase of liver-to-tumor contrast with respect to the precontrast images, allowing differential diagnosis of malignant versus benign liver lesions or metastases [14, 15, 22]. The USPIOs ( $<30 \mathrm{~nm}$ diameter) can escape the initial uptake by liver and spleen; thus, they can reach other targets that can be then indirectly detectable with MRI and thus are used as targeted contrast agents after their bioconjugation.

There are several commercially available compounds containing superparamagnetic iron oxide such as Feridex (Berlex, USA), Endorem (Guerbet, EU), and Resovist (Schering, EU, Japan). They are mostly used for liver and spleen tumors diagnosis [22]. These particles are of medium size and are coated with dextran (Feridex, Endorem) or an alkali-treated 
low molecular weight carboxydextran (Resovist). Their relaxivity $\left(r_{2}=1 / T_{2}\right)$ varies [109]: $186 \mathrm{mM}^{-1} \mathrm{~s}^{-1}$ (Resovist, $4.0 \mathrm{~nm}$ core, hydrodynamic diameter $60 \mathrm{~nm}), 120 \mathrm{mM}^{-1} \mathrm{~s}^{-1}$ (Feridex, $4.96 \mathrm{~nm}$ core, hydrodynamic diameter $160 \mathrm{~nm}$ ), and $65 \mathrm{mM}^{-1} \mathrm{~s}^{-1}$ (Combinex, $5.85 \mathrm{~nm}$ core, hydrodynamic diameter $30 \mathrm{~nm}$ ) at $1.5 \mathrm{~T}$.

Although iron oxides have been the most widely used, biomedical applications of magnetic ferrites are currently being intensely investigated. In particular, substituted magnetic spinel ferrites of the general formula $\mathrm{MFe}_{2} \mathrm{O}_{4}$ (where $\mathrm{M}=\mathrm{Zn}^{2+}, \mathrm{Mn}^{2+}, \mathrm{Co}^{2+}, \mathrm{Ni}^{2+}$, and $\mathrm{Mg}^{2+}$ ) offer the opportunity to fine-tune the magnetic properties of the inorganic nanoparticle core as a function of the kind of divalent ion [16]. Large magnetic moments, observed in these nanoparticles, are preferred for most applications, as they reduce the amount of nanoparticles needed to detect them with MRI. However, their toxic effects are often considerable and need to be reduced. Therefore, a balance between larger magnetic moments, nanoparticles concentration, and their biocompatibility is the goal of the researchers involved in the synthesis of clinically relevant nanoparticles [16].

\section{Other Nanoparticles}

As mentioned above, other than iron oxide based nanoparticles with potential clinical application in MRI and/or CT are cobalt (Co), gold $(\mathrm{Au} @ \mathrm{Fe})$, and platinum (Pt@Fe). As they have much higher saturation magnetization value than that of the iron, they have much larger effect on proton relaxation $\left(r_{1}=7.4 \mathrm{mM}^{-1} \mathrm{~s}^{-1}, r_{2}=88 \mathrm{mM}^{-1} \mathrm{~s}^{-1}\right.$ for copolymer at $1.5 \mathrm{~T}, 3.9 \mathrm{~nm}$ core diameter, $28 \mathrm{~nm}$ particle diameter [110]) providing better MR contrast than iron oxide in the same concentration and allowing smaller particle cores to be used without compromising MR sensitivity [4]. Probably the most frequently used is cobalt. While cobalt toxicity is an issue, the undesired effects of cobalt in man are difficult to evaluate, as they are also dependent on nutritional factors [111]. Many patients have taken up to $50 \mathrm{mg}$ cobalt per day as treatment of refractory anemia for long periods with little or no toxicity [4]. Most cobalt drugs also contain ferrous sulfate, which may affect the amount of cobalt absorbed, since cobalt and iron share a common absorption pathway. In contrast, $10 \mathrm{mg}$ cobalt/day taken by heavy beer drinkers in the 1960s may have resulted in cardiomyopathy [111], as the effect of inadequate protein intake, thiamine intake, zinc depletion, and alcohol may render the heart more sensitive to $\mathrm{Co}^{2+}$ toxicity [4].

As Au@Fe magnetic moment is high and it has limited reactivity, it can also be used as an MR contrast agent. There are many subtypes of gold-based nanoparticles depending on their size, shape, and physical properties. The earliest studied gold-based nanoparticles were gold nanospheres (although not exactly spherical in a strict sense). Subsequently, gold nanorods, nanoshells, and nanocages have been investigated [26]. With continued development in the synthesis techniques over the last two decades, most of these gold nanoparticles can now be produced with well-controlled size distribution.

Gold nanoparticles have recently been investigated in delivering therapeutics to the brain cancer [86, 112-114].
These nanoparticles have the advantages of relatively straightforward synthesis, easy surface functionalization, small sizes, ability to be excreted by the body and remain relatively nontoxic $[11,57,82]$. Because gold is an excellent absorber of $\mathrm{X}$-rays, it was used for improved cancer therapy. The tumors could be loaded with contrast agents containing gold increasing the radiation dose within the tumor and thus reducing unwanted radiation of normal tissue [115]. Qian et al. [116] applied gold nanoparticles for in vivo tumor targeting and detection based on pegylated gold nanoparticles and surfaceenhanced Raman scattering (SERS). Colloidal gold has been found to amplify the efficiency of Raman scattering by 14-15 orders of magnitude [116]. A gold colloid was encoded with Raman reporter molecules and covered with a layer of thiolPEG. Approximately 1.4-1.5 $\times 10^{4}$ reporter molecules were adsorbed on each $60 \mathrm{~nm}$ colloid gold [116].

One of the most interesting and promising biomedical applications of Au-based nanoparticles is their application for intracellular delivery vectors for drugs and genes $[117,118]$. Yan et al. [119] proposed one-pot-synthesized polypeptideconjugated Au nanoparticles for gene delivery and efficient transfection. In their approach, positively charged polypeptides were used to serve as capping agents as well as reductants eliminating the need for an external reducing agent. The resulting positively charged polypeptide-conjugated gold nanoparticles were applied for gene delivery due to prolonged (almost two weeks) and gradual intracellular uptake and transfection [119].

In addition to providing MRI contrast, gold nanoparticles may provide a suitable bimodal, CT, and MRI contrast $[11,42$, $83,120,121]$. It is worth to mention that gold nanoparticles have been examined by the USA National Institute of Standards and Technology as a potential standard for research based on nanosized particles $[86,97,113,114]$.

\section{Core-Shell Nanoparticles}

The very recent development in nanotechnology enabled the production of complex particles consisting of the core and shell, each made of different atoms, such as FePt@Au [109]. In principle, there are two types of core/shell nanoparticles used in imaging applications: inorganic/organic and inorganic/inorganic [122]. The most common organic shell is silica $\left(\mathrm{SiO}_{2}\right)$, while inorganic material comprises various metals. Many inorganic core-shell nanoparticles have been constructed, including Au@Ag [123], Au@Co [124],Au@Pt [125], $\mathrm{Au} \mathrm{TiO}_{2}$ [126], Au@Fe $\mathrm{O}_{3}$ [127], Ni@Ag [128], Fe@Ag [129], $\mathrm{Ni@Pt} \mathrm{[130],} \mathrm{Co@Au} \mathrm{[131],} \mathrm{Fe@Pt} \mathrm{[132],} \mathrm{LaF} 3 \mathrm{Eu}$ [133] or $\beta$ $\mathrm{NaYF}_{4}: \mathrm{Yb}^{3+}$, and $\mathrm{Er}^{3+} / \beta-\mathrm{NaYF}_{4}[134]$.

This development allowed new applications of nanoparticles, for example, as targeted contrast agents generating positive contrast in MRI. Standard contrast agents shortening $T_{2}$ have been developed, yet efficient targeted contrast agents shortening both $T_{1}$ and $T_{2}$ are still an area of research as the core/shell nanoparticles could provide improved tumor delineation and hyperintense tumor MRI due to shortening both $T_{1}$ and $T_{2}$, unlike standard iron-based nanoparticles that shorten mostly $T_{2}[43,135-137]$. These core-shell nanoparticles can be stabilized by an organic coating that can be 
pegylated for the reduction of nonspecific binding and further chemically modified for subsequent bioconjugation of the biological vehicles such as antibodies, for example, against IGFBP7 used for glioma detection [19].

\section{Production of Nanoparticles}

A commonly used method of magnetite synthesis is the coprecipitation of iron salts in aqueous media at room temperature under basic, inert conditions $[7,8]$. This relatively straightforward method results in the formation of large amounts of magnetic core clusters of about $36 \mathrm{~nm}$ composed of single particles around $10 \mathrm{~nm}$; however, the generated clusters are very polydisperse. Difficult control of aggregation and particle size distribution are the disadvantages of the coprecipitation method. An alternative to coprecipitation is the thermal decomposition method [24, 25, 34, 38, 51, 52]. In this method, an iron oleate precursor is prepared which is then decomposed into an iron oxide at high temperature in an organic solvent. The resulting nanoparticles have narrow size distributions but unfortunately are coated with a hydrophobic layer of oleic acid. In order to obtain stable aqueous dispersions of these particles in water, OA on the surface of the particles is exchanged for another ligand [35] which not only stabilizes the particle in suspension but can also serve to covalently attach other molecules to the surface of the particle [8].

The most common synthesis methods of core/shell nanoparticles are chemical vapor deposition, laser-induced assembly, self-assembly, and colloidal aggregation $[138,139]$.

In the microemulsion method [140], surfactants allow the homogenization of all types of reactants, and the particles formed are capped by the surfactant molecules [141]. Thus, the size of the nanoparticles can be controlled varying a concentration of surfactant [142]. Mandal et al. [141] used glucose to control shell growth of gold or silver onto $\mathrm{Fe}_{3} \mathrm{O}_{4}$ particles upon heating of the mixture of $\mathrm{Fe}_{3} \mathrm{O}_{4}$ particles. To cover $\mathrm{Fe}_{3} \mathrm{O}_{4}$ nanoparticles with gold or silver, a modified microemulsion method has been used [141]. This method allows shell thickness of the core-shell particles to be tunable and allowed production of structures of size from 18 to $30 \mathrm{~nm}$ with varying proportion of $\mathrm{Fe}_{3} \mathrm{O}_{4}$ to the noble metal precursor salts [141].

Very recently a very promising method of production of 3D colloidal spheres containing various nanoparticles was proposed [143]. These multifunctional nanoparticles may be used for different applications such as multimodal imaging, remotely controlled release, targeted drug delivery, or simultaneous diagnosis and therapy [144]. This so-called templateassisted fabrication process uses porous calcium $\left(\mathrm{CaCO}_{3}\right)$ microspheres as a sacrificial template. This method allows easy control of the size of the spheres, flexible tuning of their biochemical and physical properties, and encapsulation of various nanoparticles. The process comprises adsorption of nanoparticles into the porous $\mathrm{CaCO}_{3}$ sphere, encapsulation of polyelectrolytes, and removal of the template by crosslinking. The end product is a colloidal sphere. Using this method, Au nanoparticles and cross-linked poly-L-lysine (PLL) (P-AuNPs) [143], citrate-stabilized gold nanoparticles (C-AuNPs) [145], cetyl trimethylammonium bromide
(CTAB) capped gold nanorods (GNRs) [146], and magnetic nanoparticles $\left(\gamma-\mathrm{Fe}_{2} \mathrm{O}_{3}\right)$ were used to create $3 \mathrm{D}$ hybrid colloidal spheres [147].

\section{Nanoparticles for Multimodal Imaging}

While various imaging techniques, such as MRI, CT, Positron Emission Tomography (PET), and infrared (IR) imaging, have been used for diagnosis and treatment monitoring, each one delivers different information on disease and its location. There is no perfect imaging method, as each technique has its advantages and disadvantages. MRI provides the best soft tissue contrast but its sensitivity is low; PET is more sensitive than MRI but its spatial resolution is low; CT is fast but soft tissue contrast is low; and finally infrared imaging is fast and very sensitive but the depth of penetration is very low. Nanotechnology allowing production of multimodal contrast agents ("all in one") takes advantages of all these modalities.

Of particular interest is the recent development of rare earth upconversion nanophosphors (RE-UCNPs) [148-152] as potential contrast agents because of their optical and biochemical properties, such as sharp emission lines, long lifetimes, and nonphotoblinking. In particular, $\mathrm{Yb}^{3+}$ and $\mathrm{Tm}^{3+}$ codoped RE-UCNPs emitting at $800 \mathrm{~nm}$ have been used for a whole-body small-animal near-infrared imaging [153]. This technique allowed detection of only 50 cells in a wholebody mouse imaging [154]. Unfortunately, photoluminescent imaging has a low light penetration depth, but this limitation could be rectified by simultaneous application of MRI or/and CT with a contrast agent suitable for all these techniques. Therefore, $\mathrm{Gd}^{3+}$ was synthesised with RE-UCNPs creating magnetic-luminescent RE-UCNPs contrast agent for bimodal imaging, allowing $T_{1}$-enhanced MRI and upconversion luminescence imaging (UCL) [155]. Furthermore, to enable CT, MRI, and luminescence imaging using the same contrast, superparamagnetic nanoparticles have been synthesized with RE-UCNPs using a crosslinker anchoring method [156]. An example is $\mathrm{NaYF}_{4}: \mathrm{Yb}, \mathrm{Er}_{\mathrm{F}} \mathrm{Fe}_{3} \mathrm{O}_{4} @ \mathrm{Au}$, which could be used for MRI, optical, and CT imaging [157]. $\mathrm{NaYF}_{4}: \mathrm{Yb}$, $\mathrm{Tm} @ \mathrm{Fe}_{x} \mathrm{O}_{y}$ core-shell nanostructure was used for $T_{2}$ weighted MRI and UCL bimodal lymphatic imaging [158]. Of particular interest for multimodal contrasts may be $\mathrm{NaLuF}_{4}$ because RE-UCNPs based on the $\mathrm{NaLuF}_{4}$ have high UCL quantum yield [159] and high X-ray absorption coefficient. Another example of multimodal application of nanoparticles is their simultaneous utilization in high-resolution MRI and high-sensitivity PET for more accurate disease detection. The PET marker (e.g., $\mathrm{Cu}^{64}$ ) can be added to an MR marker, creating a MRI/PET contrast agent. Furthermore, radionuclide attachment can be achieved via chelating agents.

\section{Conclusions}

Recent developments in nanomaterials, molecular and cellular biology, and imaging technology enabled to enhance our diagnostic and therapeutic capabilities, improving detection limits from the tissue down to the cell and even to the molecular level. We can now combine atom and biomolecular 
manipulation applying quantum physics, molecular chemistry, biology, and genetics to fabricate minute synthetic structures $[1,160]$ and to apply them along with high-resolution noninvasive imaging technologies for diagnosis, therapy, and treatment monitoring. Current investigation of nanomaterials in animal models has offered less invasive diagnosis and induced fewer side-effects due to improved targeting, yet up to date their clinical applications have been limited. The major obstacle seems to be the long time needed for clinical trials and associated costs. Despite that nanomaterials will likely have a significant impact on patient care in the future.

\section{References}

[1] Y. Liu, H. Miyoshi, and M. Nakamura, "Nanomedicine for drug delivery and imaging: a promising avenue for cancer therapy and diagnosis using targeted functional nanoparticles," International Journal of Cancer, vol. 120, no. 12, pp. 2527-2537, 2007.

[2] R. Weissleder, "Molecular imaging in cancer," Science, vol. 312, no. 5777, pp. 1168-1171, 2006.

[3] R. Etzioni, N. Urban, S. Ramsey et al., "The case for early detection," Nature Reviews Cancer, vol. 3, no. 4, pp. 243-252, 2003.

[4] L. M. Parkes, R. Hodgson, L. T. Lu et al., "Cobalt nanoparticles as a novel magnetic resonance contrast agent-relaxivities at 1.5 and 3 Tesla," Contrast Media and Molecular Imaging, vol. 3, no. 4, pp. 150-156, 2008.

[5] J. D. G. Durán, J. L. Arias, V. Gallardo, and A. V. Delgado, "Magnetic colloids as drug vehicles," Journal of Pharmaceutical Sciences, vol. 97, no. 8, pp. 2948-2983, 2008.

[6] A. K. Gupta and M. Gupta, "Synthesis and surface engineering of iron oxide nanoparticles for biomedical applications," Biomaterials, vol. 26, no. 18, pp. 3995-4021, 2005.

[7] S. Lefebure, E. Dubois, V. Cabuil, S. Neveu, and R. Massart, "Monodisperse magnetic nanoparticles: preparation and dispersion in water and oils," Journal of Materials Research, vol. 13, no. 10, pp. 2975-2981, 1998.

[8] A.-H. Lu, E. L. Salabas, and F. Schüth, "Magnetic nanoparticles: synthesis, protection, functionalization, and application," Angewandte Chemie, vol. 46, no. 8, pp. 1222-1244, 2007.

[9] M. Latorre and C. Rinaldi, "Applications of magnetic nanoparticles in medicine: magnetic fluid hyperthermia," Puerto Rico Health Sciences Journal, vol. 28, no. 3, pp. 227-238, 2009.

[10] M. C. Roco, "Nanoscale science and engineering: unifying and transforming tools," AIChE Journal, vol. 50, no. 5, pp. 890-897, 2004.

[11] J. D. Meyers, T. Doane, C. Burda, and J. P. Basilion, "Nanoparticles for imaging and treating brain cancer," Nanomedicine, vol. 8, no. 1, pp. 123-143, 2013.

[12] S. S. Kelkar and T. M. Reineke, "Theranostics: combining imaging and therapy," Bioconjugate Chemistry, vol. 22, no. 10, pp. 1879-1903, 2011.

[13] C. N. Ramchand, P. Pande, P. Kopcansky, and R. V. Mehta, "Application of magnetic fluids in medicine and biotechnology," Indian Journal of Pure and Applied Physics, vol. 39, no. 10, pp. 683-686, 2001.

[14] Y.-X. J. Wang, S. M. Hussain, and G. P. Krestin, "Superparamagnetic iron oxide contrast agents: physicochemical characteristics and applications in MR imaging," European Radiology, vol. 11, no. 11, pp. 2319-2331, 2001.
[15] M. Taupitz, S. Schmitz, and B. Hamm, "Superparamagnetic iron oxide particles: current state and future development," RoFo Fortschritte auf dem Gebiet der Rontgenstrahlen und der Bildgebenden Verfahren, vol. 175, no. 6, pp. 752-765, 2003.

[16] M. Colombo, S. Carregal-Romero, and M. F. Casula, "Biological applications of magnetic nanoparticles," Chemical Society Reviews, vol. 41, pp. 4306-4334, 2012.

[17] O. V. Salata, "Applications of nanoparticles in biology and medicine," Journal of Nanobiotechnology, vol. 2, article 3, 2004.

[18] E. J. Werner, A. Datta, C. J. Jocher, and K. N. Raymond, "Highrelaxivity MRI contrast agents: where coordination chemistry meets medical imaging," Angewandte Chemie, vol. 47, no. 45, pp. 8568-8580, 2008.

[19] B. Tomanek, U. Iqbal, B. Blasiak et al., "Evaluation of brain tumor vessels specific contrast agents for glioblastoma imaging," Neuro-Oncology, vol. 14, no. 1, pp. 53-63, 2012.

[20] U. Iqbal, U. Trojahn, H. Albaghdadi et al., "Kinetic analysis of novel mono- and multivalent VHH-fragments and their application for molecular imaging of brain tumours," British Journal of Pharmacology, vol. 160, no. 4, pp. 1016-1028, 2010.

[21] K. Firouznia, S. Amirmohseni, M. Guiti et al., "MR relaxivity measurement of iron oxide nano-particles for MR lymphography applications," Pakistan Journal of Biological Sciences, vol. 11, no. 4, pp. 607-612, 2008.

[22] R. Lawaczeck, M. Menzel, and H. Pietsch, "Superparamagnetic iron oxide particles: contrast media for magnetic resonance imaging," Applied Organometallic Chemistry, vol. 18, no. 10, pp. 506-513, 2004.

[23] M. G. Harisinghani, J. Barentsz, P. F. Hahn et al., "Noninvasive detection of clinically occult lymph-node metastases in prostate cancer," New England Journal of Medicine, vol. 348, no. 25, pp. 2491-2499, 2003.

[24] M. H. F. Meyer, M. Stehr, S. Bhuju et al., "Magnetic biosensor for the detection of Yersinia pestis," Journal of Microbiological Methods, vol. 68, no. 2, pp. 218-224, 2007.

[25] J. E. Kirsch, "Basic principles of magnetic resonance contrast agents," Topics in Magnetic Resonance Imaging, vol. 3, no. 2, pp. $1-18,1991$.

[26] W. Cai, T. Gao, H. Hong, and J. Sun, "Applications of gold nanoparticles in cancer," Nanotechnology, Science and Applications, vol. 1, pp. 17-32, 2008.

[27] E. Duguet, S. Vasseur, S. Mornet, and J.-M. Devoisselle, "Magnetic nanoparticles and their applications in medicine," Nanomedicine, vol. 1, no. 2, pp. 157-168, 2006.

[28] C. J. Sunderland, M. Steiert, J. E. Talmadge, A. M. Derfus, and S. E. Barry, "Targeted nanoparticles for detecting and treating cancer," Drug Development Research, vol. 67, no. 1, pp. 70-93, 2006.

[29] V. Wagner, A. Dullaart, A.-K. Bock, and A. Zweck, "The emerging nanomedicine landscape,” Nature Biotechnology, vol. 24, no. 10, pp. 1211-1217, 2006.

[30] S. K. Nune, P. Gunda, P. K. Thallapally, Y.-Y. Lin, M. Laird Forrest, and C. J. Berkland, "Nanoparticles for biomedical imaging," Expert Opinion on Drug Delivery, vol. 6, no. 11, pp. 11751194, 2009.

[31] G. Orive, A. R. Gascón, R. M. Hernández, A. Domínguez-Gil, and J. L. Pedraz, "Techniques: new approaches to the delivery of biopharmaceuticals," Trends in Pharmacological Sciences, vol. 25, no. 7, pp. 382-387, 2004. 
[32] M. C. Roco, "Nanotechnology: convergence with modern biology and medicine," Current Opinion in Biotechnology, vol. 14, no. 3, pp. 337-346, 2003.

[33] I. Brigger, C. Dubernet, and P. Couvreur, "Nanoparticles in cancer therapy and diagnosis," Advanced Drug Delivery Reviews, vol. 54, no. 5, pp. 631-651, 2002.

[34] T. M. Fahmy, P. M. Fong, A. Goyal, and W. M. Saltzman, “Targeted for drug delivery," Materials Today, vol. 8, no. 8, pp. 18-26, 2005.

[35] T. M. Fahmy, R. M. Samstein, C. C. Harness, and W. M. Saltzman, "Surface modification of biodegradable polyesters with fatty acid conjugates for improved drug targeting," Biomaterials, vol. 26, no. 28, pp. 5727-5736, 2005.

[36] P. Couvreur, G. Barratt, E. Fattal, P. Legrand, and C. Vauthier, "Nanocapsule technology: a review," Critical Reviews in Therapeutic Drug Carrier Systems, vol. 19, no. 2, pp. 99-134, 2002.

[37] J. Roger, J. N. Pons, R. Massart, A. Halbreich, and J. C. Bacri, "Some biomedical applications of ferrofluids," The European Physical Journal Applied Physics, vol. 5, no. 3, pp. 321-325, 1999.

[38] F. Alexis, J.-W. Rhee, J. P. Richie, A. F. Radovic-Moreno, R. Langer, and O. C. Farokhzad, "New frontiers in nanotechnology for cancer treatment," Urologic Oncology, vol. 26, no. 1, pp. 7485, 2008.

[39] L. Zhang, F. X. Gu, J. M. Chan, A. Z. Wang, R. S. Langer, and O. C. Farokhzad, "Nanoparticles in medicine: therapeutic applications and developments," Clinical Pharmacology and Therapeutics, vol. 83, no. 5, pp. 761-769, 2008.

[40] M. Ferrari, "Cancer nanotechnology: opportunities and challenges," Nature Reviews Cancer, vol. 5, no. 3, pp. 161-171, 2005.

[41] D. A. Orringer, Y. E. Koo, T. Chen, R. Kopelman, O. Sagher, and M. A. Philbert, "Small solutions for big problems: the application of nanoparticles to brain tumor diagnosis and therapy," Clinical Pharmacology and Therapeutics, vol. 85, no. 5, pp. 531-535, 2009.

[42] S. A. Anderson, J. Glod, A. S. Arbab et al., "Noninvasive MR imaging of magnetically labeled stem cells to directly identify neovasculature in a glioma model," Blood, vol. 105, no. 1, pp. 420-425, 2005.

[43] C. M. Goodman, C. D. McCusker, T. Yilmaz, and V. M. Rotello, "Toxicity of gold nanoparticles functionalized with cationic and anionic side chains," Bioconjugate Chemistry, vol. 15, no. 4, pp. 897-900, 2004.

[44] T. R. Pisanic II, J. D. Blackwell, V. I. Shubayev, R. R. Fiñones, and S. Jin, "Nanotoxicity of iron oxide nanoparticle internalization in growing neurons," Biomaterials, vol. 28, no. 16, pp. 2572-2581, 2007.

[45] C. Wilhelm, C. Billotey, J. Roger, J. N. Pons, J.-C. Bacri, and F. Gazeau, "Intracellular uptake of anionic superparamagnetic nanoparticles as a function of their surface coating," Biomaterials, vol. 24, no. 6, pp. 1001-1011, 2003.

[46] Y. Zhang and J. Zhang, "Surface modification of monodisperse magnetite nanoparticles for improved intracellular uptake to breast cancer cells," Journal of Colloid and Interface Science, vol. 283, no. 2, pp. 352-357, 2005.

[47] J.-S. Kim, T.-J. Yoon, K.-N. Yu et al., "Cellular uptake of magnetic nanoparticle is mediated through energy-dependent endocytosis in A549 cells," Journal of Veterinary Science, vol. 7, no. 4, pp. 321-326, 2006.

[48] S. R. Bhattarai, B. K. Remant, S. Y. Kim et al., "N-hexanoyl chitosan stabilized magnetic nanoparticles: implication for cellular labeling and magnetic resonance imaging," Journal of Nanobiotechnology, vol. 6, article 1, 2008.

[49] R. Tréhin, J.-L. Figueiredo, M. J. Pittet, R. Weissleder, L. Josephson, and U. Mahmood, "Fluorescent nanoparticle uptake for brain tumor visualization," Neoplasia, vol. 8, no. 4, pp. 302-311, 2006.

[50] J. H. Clement, M. Schwalbe, N. Buske et al., "Differential interaction of magnetic nanoparticles with tumor cells and peripheral blood cells," Journal of Cancer Research and Clinical Oncology, vol. 132, no. 5, pp. 287-292, 2006.

[51] H.-Y. Lee, S.-H. Lee, C. Xu et al., "Synthesis and characterization of PVP-coated large core iron oxide nanoparticles as an MRI contrast agent," Nanotechnology, vol. 19, no. 16, Article ID 165101, 2008.

[52] P. Phanapavudhikul, S. Shen, W. K. Ng, and R. B. H. Tan, "Formulation of $\mathrm{Fe}_{3} \mathrm{O}_{4}$ /acrylate co-polymer nanocomposites as potential drug carriers," Drug Delivery, vol. 15, no. 3, pp. 177$183,2008$.

[53] W. Arap, R. Pasqualini, and E. Ruoslahti, "Cancer treatment by targeted drug delivery to tumor vasculature in a mouse model," Science, vol. 279, no. 5349, pp. 377-380, 1998.

[54] S. Dagar, M. Sekosan, B. S. Lee, I. Rubinstein, and H. Önyüksel, "VIP receptors as molecular targets of breast cancer: implications for targeted imaging and drug delivery," Journal of Controlled Release, vol. 74, no. 1-3, pp. 129-134, 2001.

[55] B. P. Eliceiri and D. A. Cheresh, "Adhesion events in angiogenesis," Current Opinion in Cell Biology, vol. 13, no. 5, pp. 563-568, 2001.

[56] C. Ehrhardt, C. Kneuer, and U. Bakowsky, "Selectins-an emerging target for drug delivery," Advanced Drug Delivery Reviews, vol. 56, no. 4, pp. 527-549, 2004.

[57] Y. Cheng, J. D. Meyers, A.-M. Broome, M. E. Kenney, J. P. Basilion, and C. Burda, "Deep penetration of a PDT drug into tumors by noncovalent drug-gold nanoparticle conjugates," Journal of the American Chemical Society, vol. 133, no. 8, pp. 2583-2591, 2011.

[58] H. Jackson, O. Muhammad, H. Daneshvar et al., "Quantum dots are phagocytized by macrophages and colocalize with experimental gliomas," Neurosurgery, vol. 60, no. 3, pp. 524-529, 2007.

[59] W.-H. Ren, J. Chang, C.-H. Yan et al., "Development of transferrin functionalized poly(ethylene glycol)/poly(lactic acid) amphiphilic block copolymeric micelles as a potential delivery system targeting brain glioma," Journal of Materials Science, vol. 21, no. 9, pp. 2673-2681, 2010.

[60] J. Chang, A. Paillard, C. Passirani et al., "Transferrin adsorption onto PLGA nanoparticles governs their interaction with biological systems from blood circulation to brain cancer cells," Pharmaceutical Research, vol. 29, pp. 1495-1505, 2012.

[61] H. Xie, Y. Zhu, W. Jiang et al., "Lactoferrin-conjugated superparamagnetic iron oxide nanoparticles as a specific MRI contrast agent for detection of brain glioma in vivo," Biomaterials, vol. 32, no. 2, pp. 495-502, 2011.

[62] L. Han, A. Zhang, H. Wang, P. Pu, C. Kang, and J. Chang, "Construction of novel brain-targeting gene delivery system by natural magnetic nanoparticles," Journal of Applied Polymer Science, vol. 121, no. 6, pp. 3446-3454, 2011.

[63] H. Gao, J. Qian, S. Cao et al., "Precise glioma targeting of and penetration by aptamer and peptide dual-functioned nanoparticles," Biomaterials, vol. 33, no. 20, pp. 5115-5123, 2012. 
64] O. Veiseh, F. M. Kievit, J. W. Gunn, B. D. Ratner, and M. Zhang, "A ligand-mediated nanovector for targeted gene delivery and transfection in cancer cells," Biomaterials, vol. 30, no. 4, pp. 649657, 2009.

[65] C. Sun, O. Veiseh, J. Gunn et al., "In vivo MRI detection of gliomas by chlorotoxin-conjugated superparamagnetic nanoprobes," Small, vol. 4, no. 3, pp. 372-379, 2008.

[66] O. Veiseh, C. Sun, C. Fang et al., "Specific targeting of brain tumors with an optical/magnetic resonance imaging nanoprobe across the blood-brain barrier," Cancer Research, vol. 69, no. 15, pp. 6200-6207, 2009.

[67] R. Kopelman, Y.-E. Lee Koo, M. Philbert et al., "Multifunctional nanoparticle platforms for in vivo MRI enhancement and photodynamic therapy of a rat brain cancer," Journal of Magnetism and Magnetic Materials, vol. 293, no. 1, pp. 404-410, 2005.

[68] G. R. Reddy, M. S. Bhojani, P. McConville et al., "Vascular targeted nanoparticles for imaging and treatment of brain tumors," Clinical Cancer Research, vol. 12, no. 22, pp. 6677-6686, 2006.

[69] H. Xin, X. Jiang, J. Gu et al., "Angiopep-conjugated poly(ethylene glycol)-co-poly( $\varepsilon$-caprolactone) nanoparticles as dual-targeting drug delivery system for brain glioma," Biomaterials, vol. 32, no. 18, pp. 4293-4305, 2011.

[70] O. Veiseh, C. Sun, J. Gunn et al., "Optical and MRI multifunctional nanoprobe for targeting gliomas," Nano Letters, vol. 5, no. 6, pp. 1003-1008, 2005.

[71] C. K. Kim, P. Ghosh, C. Pagliuca, Z.-J. Zhu, S. Menichetti, and V. M. Rotello, "Entrapment of hydrophobic drugs in nanoparticle monolayers with efficient release into cancer cells," Journal of the American Chemical Society, vol. 131, no. 4, pp. 1360-1361, 2009.

[72] H.-L. Liu, M.-Y. Hua, H.-W. Yang et al., "Magnetic resonance monitoring of focused ultrasound/magnetic nanoparticle targeting delivery of therapeutic agents to the brain," Proceedings of the National Academy of Sciences of the United States of America, vol. 107, no. 34, pp. 15205-15210, 2010.

[73] C. O. Noble, M. T. Krauze, D. C. Drummond et al., "Novel nanoliposomal CPT-11 infused by convection-enhanced delivery in intracranial tumors: pharmacology and efficacy," Cancer Research, vol. 66, no. 5, pp. 2801-2806, 2006.

[74] T. Siegal, A. Horowitz, and A. Gabizon, "Doxorubicin encapsulated in sterically stabilized liposomes for the treatment of a brain tumor model: biodistribution and therapeutic efficacy," Journal of Neurosurgery, vol. 83, no. 6, pp. 1029-1037, 1995.

[75] K. Fabel, J. Dietrich, P. Hau et al., "Long-term stabilization in patients with malignant glioma after treatment with liposomal doxorubicin," Cancer, vol. 92, no. 7, pp. 1936-1942, 2001.

[76] Z. Zhang, J. Chen, L. Ding et al., "HDL-mimicking peptide-lipid nanoparticles with improved tumor targeting," Small, vol. 6, no. 3, pp. 430-437, 2010.

[77] I. R. Corbin, J. Chen, W. Cao, H. Li, S. Lund-Katz, and G. Zheng, "Enhanced cancer-targeted delivery using engineered highdensity lipoprotein-based nanocarriers," Journal of Biomedical Nanotechnology, vol. 3, no. 4, pp. 367-376, 2007.

[78] W. Chen, P. A. Jarzyna, G. A. F. van Tilborg et al., "RGD peptide functionalized and reconstituted high-density lipoprotein nanoparticles as a versatile and multimodal tumor targeting molecular imaging probe," FASEB Journal, vol. 24, no. 6, pp. 1689-1699, 2010.

[79] I. Lynch, K. A. Dawson, and S. Linse, "Detecting cryptic epitopes created by nanoparticles," Science's STKE, vol. 2006, no. 327, article pe14, 2006.
[80] W. M. Pardridge, "CNS drug design based on principles of blood-brain barrier transport," Journal of Neurochemistry, vol. 70, no. 5, pp. 1781-1792, 1998.

[81] M. Kumar, Z. Medarova, P. Pantazopoulos, G. Dai, and A. Moore, "Novel membrane-permeable contrast agent for brain tumor detection by MRI," Magnetic Resonance in Medicine, vol. 63, no. 3, pp. 617-624, 2010.

[82] M. F. Kircher, A. de la Zerda, J. V. Jokerst et al., "A brain tumor molecular imaging strategy using a new triple-modality MRIphotoacoustic-Raman nanoparticle," Nature Medicine, vol. 18, no. 5, pp. 829-834, 2012.

[83] G. Nie, H. J. Hah, G. Kim et al., "Hydrogel nanoparticles with covalently linked coomassie blue for brain tumor delineation visible to the surgeon," Small, vol. 8, no. 6, pp. 884-891, 2012.

[84] W. M. Pardridge, "Re-engineering biopharmaceuticals for delivery to brain with molecular Trojan horses," Bioconjugate Chemistry, vol. 19, no. 7, pp. 1327-1338, 2008.

[85] R. Gabathuler, "Approaches to transport therapeutic drugs across the blood-brain barrier to treat brain diseases," Neurobiology of Disease, vol. 37, no. 1, pp. 48-57, 2010.

[86] F. Sousa, S. Mandal, C. Garrovo et al., "Functionalized gold nanoparticles: a detailed in vivo multimodal microscopic brain distribution study," Nanoscale, vol. 2, no. 12, pp. 2826-2834, 2010.

[87] P. Y. Wen and S. Kesari, "Malignant gliomas in adults," New England Journal of Medicine, vol. 359, no. 5, pp. 492-507, 2008.

[88] N. J. Ullrich and S. L. Pomeroy, "Pediatric brain tumors," Neurologic Clinics, vol. 21, no. 4, pp. 897-913, 2003.

[89] N. Y. Hernández-Pedro, E. Rangel-López, R. Magaña-Maldonado et al., "Application of nanoparticles on diagnosis and therapy in gliomas," BioMed Research International, vol. 2013, Article ID 351031, 20 pages, 2013.

[90] C. G. Hadjipanayis, R. Machaidze, M. Kaluzova et al., "EGFRvIII antibody-conjugated iron oxide nanoparticles for magnetic resonance imaging-guided convection-enhanced delivery and targeted therapy of glioblastoma," Cancer Research, vol. 70, no. 15, pp. 6303-6312, 2010.

[91] M.-Y. Hua, H.-L. Liu, H.-W. Yang et al., "The effectiveness of a magnetic nanoparticle-based delivery system for BCNU in the treatment of gliomas," Biomaterials, vol. 32, no. 2, pp. 516-527, 2011.

[92] P. M. Costa, A. L. Cardoso, L. S. Mendonça, and A. Serani, "Tumor-targeted chlorotoxin-coupled nanoparticles for nucleic acid delivery to glioblastoma cells: a promising system for glioblastoma treatment," Molecular Therapy Nucleic Acids, vol. 2, pp. 1-20, 2013.

[93] R. Mejías, S. Pérez-Yagüe, A. G. Roca et al., "Liver and brain imaging through dimercaptosuccinic acid-coated iron oxide nanoparticles," Nanomedicine, vol. 5, no. 3, pp. 397-408, 2010.

[94] R. C. Mehta, G. B. Pike, S. P. Haros, and D. R. Enzmann, “Central nervous system tumor, infection, and infarction: detection with gadolinium-enhanced magnetization transfer MR imaging," Radiology, vol. 195, no. 1, pp. 41-46, 1995.

[95] F. M. Kievit, O. Veiseh, C. Fang et al., "Chlorotoxin labeled magnetic nanovectors for targeted gene delivery to glioma," ACS Nano, vol. 4, no. 8, pp. 4587-4594, 2010.

[96] J. Y. Park, M. J. Baek, E. S. Choi et al., "Paramagnetic ultrasmall gadolinium oxide nanoparticles as advanced T1 MRI contrast agent: account for large longitudinal relaxivity, optimal particle diameter, and in Vivo T1 MR images," ACS Nano, vol. 3, no. 11, pp. 3663-3669, 2009. 
[97] Y. Cheng, J. D. Meyers, R. S. Agnes et al., "Addressing brain tumors with targeted gold nanoparticles: a new gold standard for hydrophobic drug delivery?” Small, vol. 7, no. 16, pp. 23012306, 2011.

[98] J. Jung, A. Solanki, K. A. Memoli et al., "Selective inhibition of human brain tumor cells through multifunctional quantumdot-based siRNA delivery," Angewandte Chemie, vol. 49, no. 1, pp. 103-107, 2010.

[99] S. C. J. Steiniger, J. Kreuter, A. S. Khalansky et al., "Chemotherapy of glioblastoma in rats using doxorubicin-loaded nanoparticles," International Journal of Cancer, vol. 109, no. 5, pp. 759767,2004

[100] J. M. Koziara, J. J. Oh, W. S. Akers, S. P. Ferraris, and R. J. Mumper, "Blood compatibility of cetyl alcohol/polysorbatebased nanoparticles," Pharmaceutical Research, vol. 22, no. 11, pp. 1821-1828, 2005.

[101] W. Lu, Q. Sun, J. Wan, Z. She, and X.-G. Jiang, "Cationic albumin-conjugated pegylated nanoparticles allow gene delivery into brain tumors via intravenous administration," Cancer Research, vol. 66, no. 24, pp. 11878-11887, 2006.

[102] H. Sarin, A. S. Kanevsky, H. Wu et al., "Effective transvascular delivery of nanoparticles across the blood-brain tumor barrier into malignant glioma cells," Journal of Translational Medicine, vol. 6, article 80, 2008.

[103] R. Langer, "Drug delivery and targeting," Nature, vol. 392, no. 6679, pp. S5-S10, 1998.

[104] V. P. Torchilin, "Multifunctional nanocarriers," Advanced Drug Delivery Reviews, vol. 58, no. 14, pp. 1532-1555, 2006.

[105] G. Terentyuk, G. Akchurin, I. Maksimova, G. Maslyakova, N. Khlebtsov, and V. Tuchin, "Cancer laser thermotherapy mediated by plasmonic nanoparticles," in Handbook of Photonics for Biomedical Science, pp. 763-797, 2010.

[106] K. Maier-Hauff, R. Rothe, R. Scholz et al., "Intracranial thermotherapy using magnetic nanoparticles combined with external beam radiotherapy: results of a feasibility study on patients with glioblastoma multiforme," Journal of Neuro-Oncology, vol. 81, no. 1, pp. 53-60, 2007.

[107] A. Jordan, R. Scholz, K. Maier-Hauff et al., "The effect of thermotherapy using magnetic nanoparticles on rat malignant glioma," Journal of Neuro-Oncology, vol. 78, no. 1, pp. 7-14, 2006.

[108] A. Barrefelt, M. Saghafian, R. Kuiper R et al., "Biodistribution, kinetics, and biological fate of SPION microbubbles in the rat," International Journal of Nanomedicine, vol. 8, pp. 3241-3254, 2013.

[109] H. B. Na, I. C. Song, and T. Hyeon, "Inorganic nanoparticles for MRI contrast agents," Advanced Materials, vol. 21, no. 21, pp. 2133-2148, 2009.

[110] V. B. Bregar, J. Lojk, V. Suštar, P. Veranič, and M. Pavlin, "Visualization of internalization of functionalized cobalt ferrite nanoparticles and their intracellular fate," International Journal of Nanomedicine, vol. 8, pp. 919-931, 2013.

[111] C. S. Alexander, "Cobalt-beer cardiomyopathy. A clinical and pathologic study of twenty-eight cases," The American Journal of Medicine, vol. 53, no. 4, pp. 395-417, 1972.

[112] N. Khlebtsov and L. Dykman, "Biodistribution and toxicity of engineered gold nanoparticles: a review of in vitro and in vivo studies," Chemical Society Reviews, vol. 40, no. 3, pp. 1647-1671, 2011.
[113] W. H. De Jong, W. I. Hagens, P. Krystek, M. C. Burger, A. J. A. M. Sips, and R. E. Geertsma, "Particle size-dependent organ distribution of gold nanoparticles after intravenous administration," Biomaterials, vol. 29, no. 12, pp. 1912-1919, 2008.

[114] G. Sonavane, K. Tomoda, and K. Makino, "Biodistribution of colloidal gold nanoparticles after intravenous administration: effect of particle size," Colloids and Surfaces B, vol. 66, no. 2, pp. 274-280, 2008.

[115] J. F. Hainfeld, F. A. Dilmanian, D. N. Slatkin, and H. M. Smilowitz, "Radiotherapy enhancement with gold nanoparticles," Journal of Pharmacy and Pharmacology, vol. 60, no. 8, pp. 977-985, 2008.

[116] X. Qian, X.-H. Peng, D. O. Ansari et al., "In vivo tumor targeting and spectroscopic detection with surface-enhanced Raman nanoparticle tags," Nature Biotechnology, vol. 26, no. 1, pp. 8390, 2008.

[117] P. Ghosh, G. Han, M. De, C. K. Kim, and V. M. Rotello, "Gold nanoparticles in delivery applications," Advanced Drug Delivery Reviews, vol. 60, no. 11, pp. 1307-1315, 2008.

[118] D. A. Giljohann, D. S. Seferos, W. L. Daniel, M. D. Massich, P. C. Patel, and C. A. Mirkin, "Gold nanoparticles for biology and medicine," Angewandte Chemie, vol. 49, no. 19, pp. 3280-3294, 2010.

[119] X. Yan, J. Blacklock, J. Li, and H. Möhwald, “One-pot synthesis of polypeptide-gold nanoconjugates for in vitro gene transfection," ACS Nano, vol. 6, no. 1, pp. 111-117, 2012.

[120] R. Popovtzer, A. Agrawal, N. A. Kotov et al., "Targeted gold nanoparticles enable molecular CT imaging of cancer," Nano Letters, vol. 8, no. 12, pp. 4593-4596, 2008.

[121] L. Faucher, A.-A. Guay-Bégin, J. Lagueux, M.-F. Côté, É. Petitclerc, and M.-A. Fortin, "Ultra-small gadolinium oxide nanoparticles to image brain cancer cells in vivo with MRI," Contrast Media and Molecular Imaging, vol. 6, no. 4, pp. 209-218, 2011.

[122] R. Ghosh Chaudhuri and S. Paria, "Core/shell nanoparticles: classes, properties, synthesis mechanisms, characterization, and applications," Chemical Reviews, vol. 112, no. 4, pp. 2373-2433, 2012.

[123] R. Güzel, Z. Üstündaĝ, H. Ekşi et al., "Effect of Au and Au@Ag core-shell nanoparticles on the SERS of bridging organic molecules," Journal of Colloid and Interface Science, vol. 351, no. 1, pp. 35-42, 2010.

[124] F. Bao, J. F. Li, B. Ren, J. Yao, R. Gu, and Z. Tian, "Synthesis and characterization of Au@Co and Au@Ni core-shell nanoparticles and their applications in surface-enhanced Raman spectroscopy," Journal of Physical Chemistry C, vol. 112, pp. 345-350, 2008.

[125] S. Kumar and S. Zou, "Electrooxidation of carbon monoxide and methanol on platinum-overlayer- coated gold nanoparticles: effects of film thickness," Langmuir, vol. 23, no. 13, pp. 7365-7371, 2007.

[126] Y. Chen, B. Zhu, M. Yao, S. Wang, and S. Zhang, "The preparation and characterization of $\mathrm{Au} @ \mathrm{TiO}_{2}$ nanoparticles and their catalytic activity for CO oxidation," Catalysis Communications, vol. 11, no. 12, pp. 1003-1007, 2010.

[127] H. Yin, Z. Ma, M. Chi, and S. Dai, "The preparation and characterization of $\mathrm{Au} @ \mathrm{TiO}_{2}$ nanoparticles and their catalytic activity for CO oxidation," Catalysis Today, vol. 160, pp. 87-95, 2011.

[128] L. Xia, X. Hu, X. Kang, H. Zhao, M. Sun, and X. Cihen, "A onestep facile synthesis of $\mathrm{Ag}-\mathrm{Ni}$ core-shell nanoparticles in waterin-oil microemulsions," Colloids and Surfaces A, vol. 367, no. 1-3, pp. 96-101, 2010. 
[129] L. Lu, W. Zhang, D. Wang, X. Xu, J. Miao, and Y. Jiang, "Fe@Ag core-shell nanoparticles with both sensitive plasmonic properties and tunable magnetism," Materials Letters, vol. 64, pp. 1732-1734, 2010.

[130] G. Wang, H. Wu, D. Wexler, H. Liu, and O. Savadogo, “Ni@Pt core-shell nanoparticles with enhanced catalytic activity for oxygen reduction reaction," Journal of Alloys and Compounds, vol. 503, no. 1, pp. L1-L14, 2010.

[131] W. R. Lee, M. Kim, and J. Choi, "Redox-transmetalation process as a generalized synthetic strategy for core-shell magnetic nanoparticles," Journal of Analytical and Applied Chemistry, vol. 127, pp. 16090-16097, 2005.

[132] X.-B. Zhang, J.-M. Yan, S. Han, H. Shioyama, and Q. Xu, "Magnetically recyclable Fe@Pt core-shell nanoparticles and their use aselectrocatalysts for ammonia borane oxidation: the role of crystallinity of thecore," Journal of the American Chemical Society, vol. 131, no. 8, pp. 2778-2779, 2009.

[133] J. W. Stouwdam and F. C. J. M. van Veggel, "Improvement in the luminescence properties and processability of $\mathrm{LaF}_{3} / \mathrm{Ln}$ and $\mathrm{LaPO}_{4} / \mathrm{Ln}$ nanoparticles by surface modification," Langmuir, vol. 20, no. 26, pp. 11763-11771, 2004.

[134] Y. Wang, L. Tu, J. Zhao, Y. Sun, X. Kong, and H. Zhang, "Upconversion luminescence of $\beta-\mathrm{NaYF}_{4}: \mathrm{Yb}^{3+}, \mathrm{Er}^{3+} \beta-\mathrm{NaYF}_{4}$ core/ shell nanoparticles: excitation power density and surface dependence," Journal of Physical Chemistry C, vol. 113, no. 17, pp. 71647169, 2009.

[135] N. J. J. Johnson, W. Oakden, G. J. Stanisz, R. Scott Prosser, and F. C. J. M. van Veggel, "Size-tunable, ultrasmall $\mathrm{NaGdF}_{4}$ nanoparticles: insights into their $\mathrm{T}_{1}$ MRI contrast enhancement," Chemistry of Materials, vol. 23, no. 16, pp. 3714-3722, 2011.

[136] G. K. Das, N. J. J. Johnson, J. Cramen et al., "NaDyF 4 nanoparticles as $\mathrm{T}_{2}$ contrast agents for ultrahigh field magnetic resonance imaging," Journal of Physical Chemistry Letters, vol. 3, no. 4, pp. 524-529, 2012.

[137] C. Dong, A. Korinek, B. Blasiak, B. Tomanek, and F. C. J. M. van Veggel, "Cation exchange: a facile method to make $\mathrm{NaYF}_{4}: \mathrm{Yb}, \mathrm{Tm}-\mathrm{NaGdF}_{4}$ core-shell nanoparticles with a thin, tunable, and uniform shell," Chemistry of Materials, vol. 27, no. 4, pp. 1297-1305, 2012.

[138] Y. Y. Wang, K. F. Cai, and X. Yao, "Facile synthesis of PbTe nanoparticles and thin films in alkaline aqueous solution at room temperature," Journal of Solid State Chemistry, vol. 182, no. 12, pp. 3383-3386, 2009.

[139] S.-H. Yoo, L. Liu, and S. Park, "Nanoparticle films as a conducting layer for anodic aluminum oxide template-assisted nanorod synthesis," Journal of Colloid and Interface Science, vol. 339, no. 1, pp. 183-186, 2009.

[140] M. A. López-Quintela and J. Rivas, "Chemical reactions in microemulsions: a powerful method to obtain ultrafine particles," Journal of Colloid and Interface Science, vol. 158, no. 2, pp. 446-451, 1993.

[141] M. Mandal, S. Kundu, S. K. Ghosh et al., "Magnetite nanoparticles with tunable gold or silver shell," Journal of Colloid and Interface Science, vol. 286, no. 1, pp. 187-194, 2005.

[142] M. Mandal, S. Kundu, T. K. Sau, S. M. Yusuf, and T. Pal, "Synthesis and characterization of superparamagnetic Ni-Pt nanoalloy," Chemistry of Materials, vol. 15, no. 19, pp. 3710-3715, 2003.

[143] X. Yan, J. Li, and H. Mohwald, "Templating assembly of multifunctional hybrid colloidal spheres," Advanced Materials, vol. 24, pp. 2663-2667, 2012.
[144] X. Yan, P. Zhu, J. Fei, and J. Li, "Self-assembly of peptideinorganic hybrid spheres for adaptive encapsulation of guests," Advanced Materials, vol. 22, no. 11, pp. 1283-1287, 2010.

[145] S. Link and M. A. El-Sayed, "Size and temperature dependence of the plasmon absorption of colloidal gold nanoparticles," Journal of Physical Chemistry B, vol. 103, no. 21, pp. 4212-4217, 1999.

[146] B. Nikoobakht and M. A. El-Sayed, "Preparation and growth mechanism of gold nanorods (NRs) using seed-mediated growth method," Chemistry of Materials, vol. 15, no. 10, pp. 19571962, 2003

[147] J. Johnson and F. C. J. M. van Veggel, "Sodium lanthanide fluoride core-shell nanocrystals: a general perspective on epitaxial shell growth," Nano Research, 2013.

[148] J. Zhou, Z. Liu, and F. Li, "Upconversion nanophosphors for small-animal imaging," Chemical Society Reviews, vol. 41, no. 3, pp. 1323-1349, 2012.

[149] J. Shen, L.-D. Sun, and C.-H. Yan, "Luminescent rare earth nanomaterials for bioprobe applications," Dalton Transactions, no. 42 , pp. $5687-5697,2008$.

[150] X. Zhu, J. Zhou, M. Chen, M. Shi, W. Feng, and F. Li, "Core-shell $\mathrm{Fe}_{3} \mathrm{O}_{4} @ \mathrm{NaLuF}_{4}: \mathrm{Yb}, \mathrm{Er} / \mathrm{Tm}$ nanostructure for MRI, CT and upconversion luminescence tri-modality imaging," Biomaterials, vol. 33, no. 18, pp. 4618-4627, 2012.

[151] F. Wang, Y. Han, C. S. Lim et al., "Simultaneous phase and size control of upconversion nanocrystals through lanthanide doping," Nature, vol. 463, no. 7284, pp. 1061-1065, 2010.

[152] S. Wu, G. Han, D. J. Milliron et al., "Non-blinking and photostable upconverted luminescence from single lanthanide-doped nanocrystals," Proceedings of the National Academy of Sciences of the United States of America, vol. 106, no. 27, pp. 10917-10921, 2009 .

[153] M. Nyk, R. Kumar, T. Y. Ohulchanskyy, E. J. Bergey, and P. N. Prasad, "High contrast in vitro and in vivo photoluminescence bioimaging using near infrared to near infrared up-conversion in $\mathrm{Tm}^{3+}$ and $\mathrm{Yb}^{3+}$ doped fluoride nanophosphors," Nano Letters, vol. 8, no. 11, pp. 3834-3838, 2008.

[154] Q. Liu, Y. Sun, T. Yang, W. Feng, C. Li, and F. Li, "Sub-10 nm hexagonal lanthanide-doped $\mathrm{NaLuF}_{4}$ upconversion nanocrystals for sensitive bioimaging in vivo," Journal of the American Chemical Society, vol. 133, no. 43, pp. 17122-17125, 2011.

[155] J. Zhou, Y. Sun, X. Du, L. Xiong, H. Hu, and F. Li, “Dual-modality in vivo imaging using rare-earth nanocrystals with nearinfrared to near-infrared (NIR-to-NIR) upconversion luminescence and magnetic resonance properties," Biomaterials, vol. 31, no. 12, pp. 3287-3295, 2010.

[156] J. Shen, L.-D. Sun, Y.-W. Zhang, and C.-H. Yan, "Superparamagnetic and upconversion emitting $\mathrm{Fe}_{3} \mathrm{O}_{4} / \mathrm{NaYF}_{4}$ : $\mathrm{Yb}$,Er heteronanoparticles via a crosslinker anchoring strategy," Chemical Communications, vol. 46, no. 31, pp. 5731-5733, 2010.

[157] L. Cheng, K. Yang, Y. Li et al., "Facile preparation of multifunctional upconversion nanoprobes for multimodal imaging and dual-targeted photothermal therapy," Angewandte Chemie, vol. 50, no. 32, pp. 7385-7390, 2011.

[158] A. Xia, Y. Gao, J. Zhou et al., "Core-shell $\mathrm{NaYF}_{4}: \mathrm{Yb}^{3+}, \mathrm{Tm}^{3+}$ @FexOy nanocrystals for dual-modality $\mathrm{T}_{2}$-enhanced magnetic resonance and NIR-to-NIR upconversion luminescent imaging of small-animal lymphatic node," Biomaterials, vol. 32, no. 29, pp. 7200-7208, 2011. 
[159] T. Yang, Y. Sun, Q. Liu, W. Feng, P. Yang, and F. Li, “Cubic sub$20 \mathrm{~nm} \mathrm{NaLuF}$-based upconversion nanophosphors for highcontrast bioimaging in different animal species," Biomaterials, vol. 33, no. 14, pp. 3733-3742, 2012.

[160] S. E. McNeil, "Nanotechnology for the biologist," Journal of Leukocyte Biology, vol. 78, no. 3, pp. 585-594, 2005. 

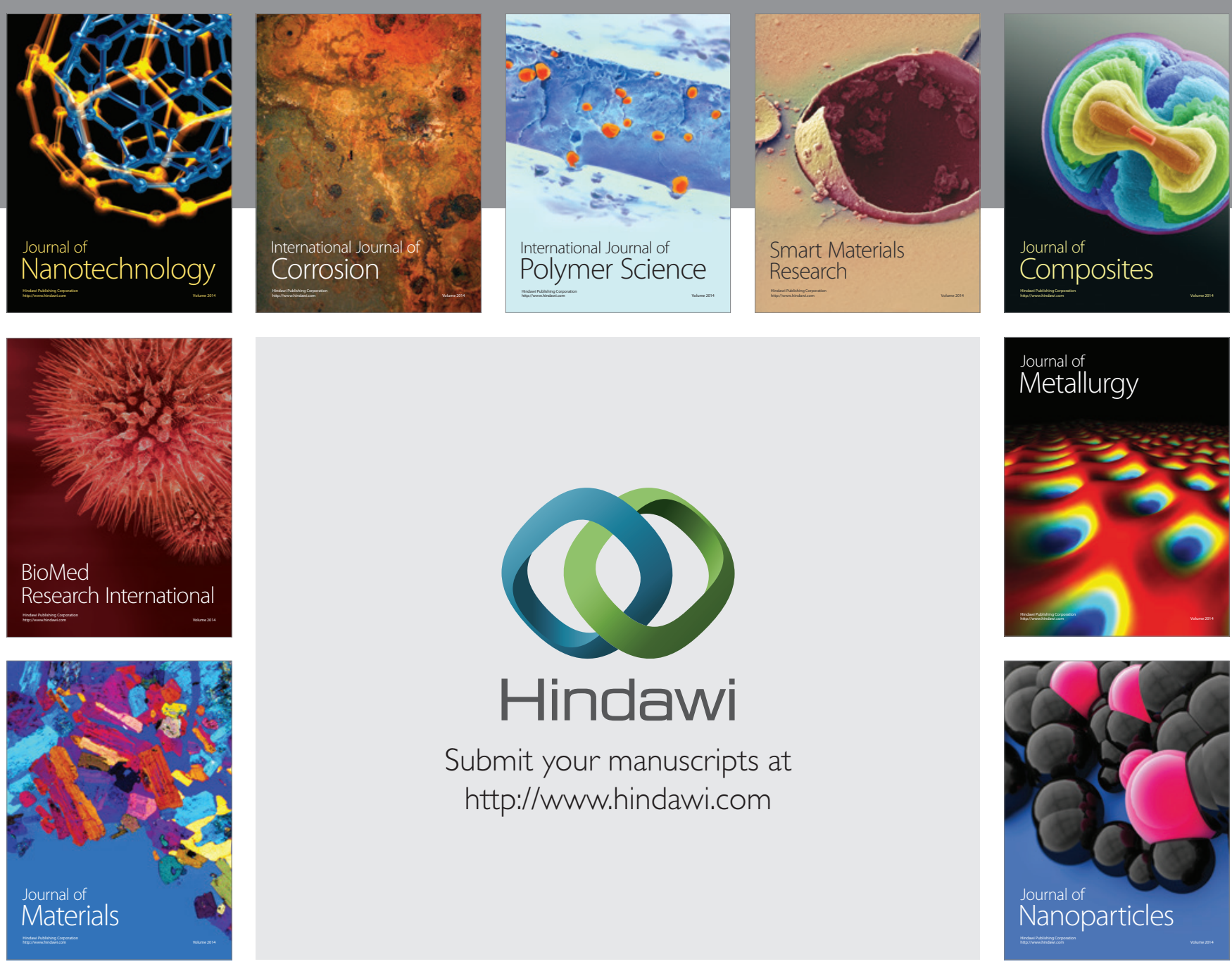

Submit your manuscripts at http://www.hindawi.com
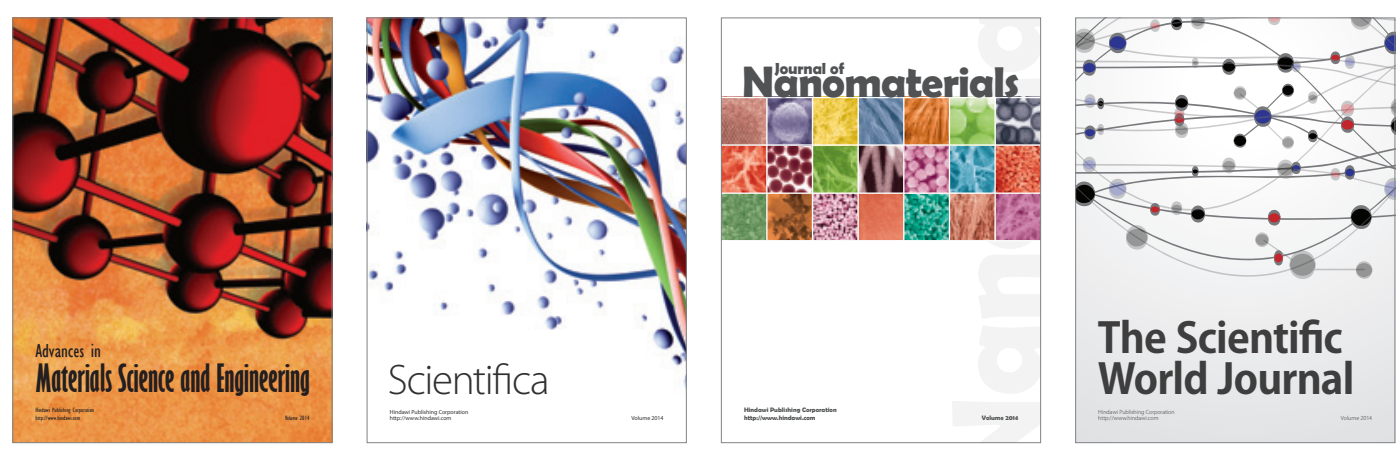

\section{The Scientific World Journal}
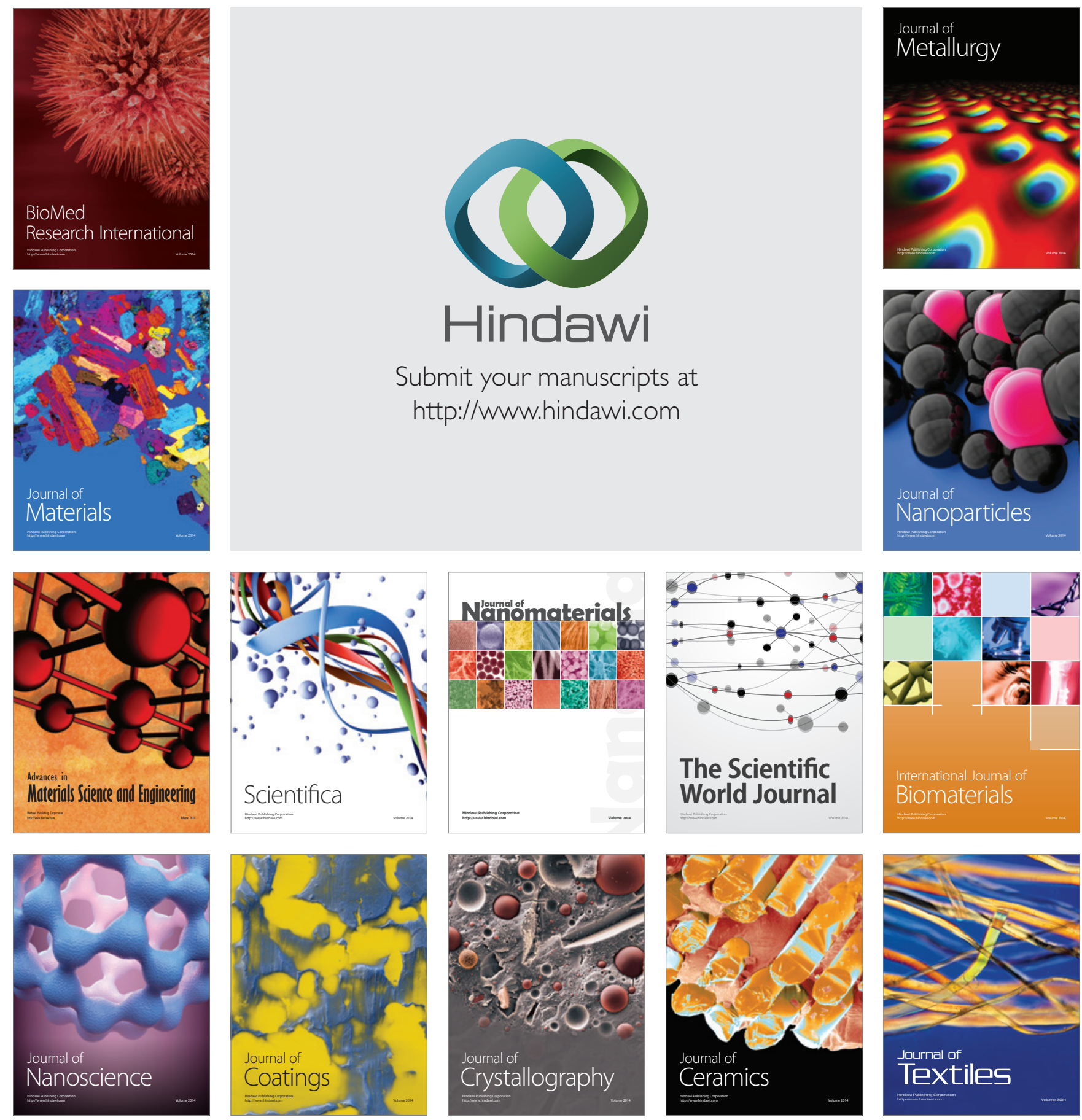